\title{
Assessing the Impacts of Natural Resource Management Interventions in Agriculture: Concepts, Issues and Challenges
}

\author{
H.A. Freeman 1 , B. Shiferaw ${ }^{2}$ and S.M. Swinton ${ }^{3}$ \\ 'International Livestock Research Institute (ILRI), Nairobi, Kenya \\ ${ }^{2}$ International Crops Research Institute for the Semi-Arid Tropics (ICRISAT), \\ Nairobi, Kenya \\ ${ }^{3}$ Michigan State University, East Lansing, Michigan, USA
}

\section{Introduction}

One of the greatest development challenges facing the world in the $21^{\text {st }}$ century is meeting the rising demand for food while maintaining the sustainability of the natural resource base. Increases in per capita income, population growth and urbanisation are expected to double global food demand in the next $40-50$ years. The demand for cereals is estimated to increase from 1.9 billion tonnes ( $\mathrm{t}$ ) in 1997 to 2.5 billion $\mathrm{t}$ by 2020 and for meat from 209 million $\mathrm{t}$ to 327 million $t$ (Rosegrant et al., 2001). These trends in food demand have important implications for natural resources that provide essential support to life and economic processes.

Natural resource management (NRM) aims for the efficient and sustainable utilisation of renewable and non-renewable natural resources. In the context of this book, NRM in agriculture refers to human administration and sustainable utilisation of biophysical resources for the production of food, feed, fibre and fuel. Production in this sense entails direct husbandry, including such activities as aquaculture and planted forests, but does not include hunting, fishing and gathering of uncultivated species. Natural resources of interest include all those affected by the production process (e.g. soil, water, biodiversity, fish and forests). Accordingly, depending on the resource and environmental service flows affected, impact assessment of NRM in agriculture includes the associated changes in the environmental impacts of agricultural production.

Well-managed natural resources generate flows of benefits that provide the basis for maintaining and improving livelihoods, improve the quality 
of life, and contribute to sustainable growth. Agricultural production worldwide mostly depends on soil, providing the most important source of livelihoods for the majority of rural people in the developing world. Water is essential for sustaining human populations and, indeed, all species. It is also a key input in agricultural and industrial production and processing as well as an important sink for discharging waste. Fish are an important biological resource that account for $20 \%$ of the animal-derived protein consumption in low-income countries and about 13\% in the developed countries (Delgado et al., 2003). With increasing intensification of food production, aquaculture is becoming an important source of income and livelihoods in many parts of the world. Forests and forest resources, including agroforestry and tree crops, provide a source of livelihoods for over 1.6 billion people worldwide. Forests also contain at least $80 \%$ of the remaining global biodiversity, they help to protect water resources, and they are a significant carbon sink mitigating climate change (World Bank, 2001). Biodiversity enables animal and crop improvement programmes that maintain and increase productivity. Properly managed natural resources provide an essential foundation for reducing poverty and promoting sustainable growth.

However, the combined effects of population growth, higher levels of economic activity per capita, and mismanagement are putting increasing pressure on the natural resource base. There is abundant evidence of natural resources degradation worldwide. Over the past 45 years an estimated 1.2 billion ha has been degraded as a result of human activity. This affects more than 900 million people in 100 countries. Erosion, salinisation, compaction, and other forms of degradation afflict 30\% of the world's irrigated lands, $40 \%$ of rainfed agricultural lands, and $70 \%$ of rangelands. Every year an additional 12-15 million ha of forests are lost to deforestation. The world is facing a systemic water crisis resulting from the unsustainable use and management of water resources. New threats and challenges to water supplies arise from urbanisation, over-extraction of surface and ground water, pollution, and loss of aquatic biodiversity (World Bank, 2001).

Degradation of natural resources has real economic, social, and human costs with substantial impacts on national economies. It also directly threatens the long-term growth of agricultural productivity, food security, and the quality of life, particularly in developing countries. Investments in agricultural research have resulted in dramatic increases in food production generated from higher-yielding crop varieties with improved resistance to pests and diseases, mostly in areas of high agricultural potential in developing countries. The dramatic increase in production of rice, maize and wheat, referred to as the Green Revolution - was credited with averting widespread per capita food shortages and starvation in the later half of the 20th century, particularly in Asia and Latin America. The short-term crop productivity gains of the Green Revolution are however associated with long-term degradation of soils, water, biodiversity, and marginal lands. Pingali and Rosegrant (1998) provided empirical evidence linking the intensification of rice-wheat systems in the Indo-Gangetic plains of South Asia to the build up of salinity and waterlogging, depletion of groundwater resources, formation of hard 
pans, soil nutrient deficiencies, and increased incidence of soil toxicity. Thus, while improving agricultural productivity is an essential component in many poverty-reduction and growth strategies, degradation of natural resources can threaten the achievement of this objective.

Natural resource degradation is particularly costly for the poor. Poor people often depend directly on natural resources for their livelihoods, making them especially vulnerable when natural resources lose their productive potential. There is growing awareness that sustainable use of natural resources can contribute to poverty alleviation and improvements in human welfare. Project, programme, or policy interventions that improve the management of natural resources can lead to significant economic gains that directly benefit poor people, resulting in substantial improvements in their welfare.

The linkages between sustainable management of natural resources and improvements in the well being of the poor have contributed to a resurgence in development lending and research investments on environment and NRM over the past two decades. The World Bank, for example, is increasing lending for environment and NRM issues after a period of decline over the last few years. In 2003 US $\$ 1.1$ billion was allocated for environmental and NRM issues, representing $6 \%$ of overall lending, an increase from $4.7 \%$ in 2002 (World Bank, 2003). Similarly, international organisations focusing on sustainable increase in agricultural productivity and improvement in rural livelihoods such as the Consultative Group on International Agricultural Research (CGIAR), have increased the share of NRM research in their overall research portfolio (Kelley and Gregersen, Chapter 15, this volume). Between 1994 and 2001, CGIAR research investments in protecting the environment rose from 15 to $19 \%$ of total resource allocation, while investment on biodiversity almost doubled from 6 to 11\% (Barrett, 2003). These trends in resource allocation generally reflect the growing consensus that the objectives of poverty alleviation, food security, and sustainable management of natural resources are highly interdependent.

This chapter identifies key issues involved in assessing the impacts of NRM interventions. Such interventions include adoption of changed NRM practices arising from investments in research and outreach that are implemented through NRM projects, programmes, and policies. The focus is on impact analysis of NRM interventions, not on conducting NRM projects per se. The next sections discuss the purposes of impact assessment, followed by the underlying concepts and techniques for conducting impact assessment. This is followed by a discussion of the special challenges that complicate impact assessment of NRM interventions. The chapter ends by providing an overview of the conceptual and empirical approaches for NRM impact assessment. 


\section{Why Assess NRM Impacts?}

Impact assessment should enhance the understanding of the extent to which project, programme, and policy interventions affect the target population and the magnitude of these intervention effects on the welfare of the intended beneficiaries. Resources are limited and managers in research and development institutions are under pressure to allocate available resources efficiently and effectively.

Impact assessment, whether it is backward-looking, evaluating the impact of past research and development (R\&D) investments (ex post impact assessment) or forward-looking, evaluating the impact of current and future R\&D investments (ex ante impact assessment) should help in setting priorities over competing interventions and inform policy decisions on efficient allocation of scarce resources.

Impact assessment can be used to measure the outcomes and impact of development interventions, aiming to discern intervention effects from the influence of other external factors. As noted above, this is particularly challenging with NRM interventions.

Donors, policy makers, and development managers need information to monitor progress in achieving outputs and outcomes, providing a basis to demonstrate results, and strengthening accountability for results that may justify continued funding. Often, broad indicators of impact such as aggregate rates of returns to investments and benefit-cost ratios are used as indicators to provide evidence of the effectiveness of past and future interventions. These indicators are used to make decisions on whether to expand, adjust, or drop project, programme, or policy interventions. Ex post evaluation also provides lessons that could be used to improve the design and management of service delivery and other future interventions. Comprehensive impact assessment that includes both productivity and environmental and sustainability impacts provides an objective basis for comparing the effectiveness of alternative interventions in achieving the stated welfare and sustainability objectives. Such information is useful for planning, setting priorities, and allocating resources to alternative interventions. However, evaluating the actual livelihood and poverty impacts of agricultural and NRM interventions would require analysis of distributional and equity impacts in addition to computation of such simple efficiency indicators as net present values, benefit-cost ratios, and internal rates of return. New methods and approaches are needed to extend traditional impact assessments to address such policyrelevant concerns.

R\&D organisations are increasingly interested in assessing abroad range of impacts from NRM interventions. This, however, requires examining a range of multi-dimensional impacts that may include impacts on the quality of the resource base as well as the flow of ecosystem services that provide basic life support functions in agro-ecosystems. These non-market benefit objectives imply that conventional economic impact analyses are fundamentally incompatible with measuring the benefits that NRM projects seek to obtain. Methodological development in the approaches and techniques for valuation 
of ecosystem and environmental goods and services is enabling assessment of environmental impacts associated with NRM interventions that have been largely neglected in past impact assessment studies.

Nevertheless, methods for assessing the multi-faceted impacts from NRM interventions are far less developed than methods for assessing impact for crop improvement research (Izac, 1998; Shiferaw and Freeman, 2003). This explains, in part, the dearth of credible quantitative evidence, ex ante or ex post, that assesses the impact of NRM research compared to the evidence on the effects of crop improvement research. For example, of the 1886 rates of return on research investment reviewed by Alston et al. (2000) over 50\% were for crops research, while NRM research accounted for less than 5\%. The limited number of studies on NRM impact assessment, despite the increased interest on sustainability issues, suggests that tracing the practical linkages between NRM interventions with changes in the resource base, the environment, and human welfare is fraught with complexities (Nelson and Maredia, 1999). The specific challenges and empirical difficulties that impact evaluators face in undertaking valid and plausible assessment of NRM impacts are discussed below.

\section{Impact Assessment: Concepts and Processes}

In the literature, the term 'impact assessment' is used interchangeably with 'impact evaluation'. Impact assessment determines the welfare changes from a given intervention on individuals, households and institutions and whether those changes are attributable to the project, programme, or policy intervention (Baker, 2000; World Bank, 2002).

Impact assessments are often undertaken ex ante, evaluating the impact of current and future interventions, or ex post, evaluating the impact of past intervention. Impact assessment can also be made concurrently within the project cycle. Ex ante assessment intends to inform policy decisions as to whether a proposed project or programme intervention should be carried out at all. Such evaluations gather information on the likely economic and environmental impacts and how the flow of costs and benefits is distributed across the affected populations. The distributional impacts and identification of winners and losers are critical elements in evaluating the social impacts of proposed interventions. The ex ante assessment compares the expected benefits and costs over time along with the anticipated social impacts. Such information is often used to prioritise interventions and inform policy choice as to whether the expected social benefits would outweigh the costs - to justify implementation of proposed interventions. Ex post impact assessments gener-ally intend to measure realised benefits and costs of programme interventions to see whether stated objectives have been met and whether the realised benefits indeed outweigh the direct and indirect costs incurred. Ex post assessment also attempts to understand the pathway through which observed impacts have occurred and why interventions fail or succeed in attaining stated objectives. Hence, ex post assessments can inform policy 
choices as to whether related planned programme interventions should be discontinued, modified, improved or sustained in the future.

An important aspect of impact assessment is to understand how interventions affect the beneficiaries or affected populations and whether any outcomes and improvements are a direct result of the intervention. An intervention will not enhance economic efficiency unless the realised or anticipated benefits exceed the overall costs. In cases where the desired impact is not being achieved, the evaluation can also provide useful information on how the programme design could be improved.

Measuring project outcomes alone is not sufficient to assess impacts. In many cases, there may be other factors or events that affect outcomes other than the project itself. For example, if an agroforestry outreach project is initiated and shortly thereafter the national government ceases to subsidise imported fertiliser, farmers may begin to rely upon agroforestry methods to meet crop nutritional needs. In order to measure the real impact of the agroforestry outreach intervention, it is important to control for other confounding factors such as the subsidy termination, and to net out those outcomes that can be attributed only to the intervention itself. This means that impact assessment must estimate the counterfactual, i.e. what would have happened had the intervention never taken place.

Determining the counterfactual is at the core of evaluation design (Baker, 2000). Three broad quantitative methods can be used to identify an appropriate counterfactual (Heckman and Robb, 1985; Heckman and Smith, 1995), including estimation methods used with randomised experimental design, non-randomised quasi-experimental methods, and non-experimental designs.

In the experimental design approach, groups are selected randomly from the same population as the programme participants, while the control group is randomly assigned among those who do not receive the programme. The control group should resemble the treatment group in every sense, with the only difference between the two being the presence of the programme intervention in the treatment group. The main benefit of this technique is the simplicity in interpreting the results - intervention impact can be estimated by the mean difference between the treatment and control groups. While the experimental design is considered the ideal and most robust approach to estimating intervention impacts, it has several disadvantages. Firstly, randomisation, which involves denial of benefits for a certain group of people, may not be ethically acceptable for many interventions. Secondly, randomisation may not be politically acceptable. Thirdly, the proposed project, programme or policy may have economy-wide effects that make randomisation unfeasible. Fourthly, experimental designs may be technically impossible (e.g. due to mobile populations) or expensive and tedious to implement. ${ }^{1}$ These difficulties often limit the practical usefulness of the experimental design approach for establishing a valid counterfactual.

Quasi-experimental designs such as matching, reflexive comparison, and double difference methods, and non-experimental designs, such as instrumental variables methods, can be used when it is not possible to construct 
treatment and comparison groups through experimental design. Matching involves identifying non-programme participants comparable in essential characteristics to programme participants to be matched on the basis of common characteristics that are believed to influence programme outcomes. The propensity score matching approach that is based on the predicted probability of participation given observed characteristics is the most commonly used approach for matching. The reflexive comparison method compares programme participants before and after the programme. The double difference method compares both programme participants and nonparticipants before and after the programme. Instrumental variables consist of using 'instruments' that matter to participation but not to outcomes given participation, allowing identification of exogenous variation in outcomes attributable to the programme, while recognising that its placement may not be random but purposive. Instrumental variables are first used to predict programme participation; then the programme impact is estimated using predicted values from the first equation (Baker, 2000).

Selection bias is a major challenge to measuring programme impacts in non-experimental settings. Selection bias occurs when pre-existing conditions skew outcomes in a way that is not truly attributable to the programme intervention. For example, if farmers with the best land adopt a practice of soil conservation faster than farmers with poor land, the yield gain they achieve may exceed what other farmers could expect, due to their higher land quality. When bias exists, the assessment may provide inaccurate results that could lead to erroneous inferences and conclusion about the impacts of the intervention (Friedlander and Robins, 1995). Randomised experiments avoid selection bias through random selection. The quasi-experimental and non-experimental designs must rely upon statistical methods to minimise bias due to non-random data. Certain statistical methods allow comparison of programme participants and non-participants while controlling for the process of selection (Pender, Chapter 6, this volume; Greene, 1997; Baker, 2000). However, these methods tend to be less robust statistically than ones that use experimental data. Moreover, the statistical methods for correcting selection bias can be quite complex (e.g. Kerr, 2001), and it is often difficult to fully correct for it in practice (Baker, 2000).

Qualitative methods are also used for impact assessment. Such methods seek to determine impacts by relying on methods other than the counterfactual (Mohr, 1995). Qualitative approaches involve understanding the processes, behaviours and conditions surrounding NRM interventions. Often qualitative methods are participatory, relying upon the perceptions of the individuals or groups being studied (Valadez and Bamberger, 1994). Qualitative approaches tend to use open-ended designs for data collection, including focus group discussions, key informant surveys, and participatory appraisals. Examples can be found in Chapters 11 (Bantilan et al.) and 14 (Douthwaite et al.) in this volume. Commonly used analytical tools include stakeholder analysis and beneficiary assessment. Qualitative approaches provide insights into the way in which households and communities perceive a project and how they feel affected by it. Qualitative methods can be simple, quick, flexible, and tailored 
to specific socio-economic conditions. However the subjectivity involved in data collection, the lack of a counterfactual and limited statistical rigour make the results less conclusive and more difficult to generalise than quantitative assessments.

Qualitative approaches are increasingly used in conjunction with quantitative approaches (Baker, 2000), and such combinations can enhance the validity and reliability of impact evaluations (Bamberger, 2000). While quantitative approaches allow statistical tests for causality and isolation of programme effects from other confounding influences, qualitative methods allow in-depth study of selected issues and help the evaluator find explanations for the results obtained in the quantitative analysis. In short, quantitative methods excel at answering impact assessment questions about 'what' and 'how much', whereas qualitative methods are preferred for exploring questions of 'how' and 'why'. A mix of quantitative and qualitative approaches is ideal because it provides the quantifiable impacts of the intervention as well as an explanation of the processes and relationships that yielded such outcomes.

Theevaluation design chosen for NRMimpactassessmentneeds to capture the special features, complexities and multiple outcomes associated with such interventions. For example, assessing the impacts of NRM technology and policy interventions requires accounting for both the tangible and the lesstangible and diffuse productivity and environmental impacts. The process of tracking these relationships and impact pathways may involve several steps. Nelson and Maredia (1999) discussed five steps in assessing environmental costs and benefits in NRM projects. These steps involve:

- Understanding the causes and impact of changes in the use of natural resources such as declining soil fertility, land degradation, water pollution, deforestation, loss of biodiversity, etc.

- Identifying the main types of economic costs and benefits. Economic costs could include depletion of the stock of natural resources and species losses. An important consideration is to identify the distribution of the burden of these costs over time and space and across affected communities

- Determining whether or not there is a means to measure costs and benefits in monetary terms

- Assessing the extent of changes in the use of natural resources and the environmental consequences resulting from these changes. This includes collecting data to estimate the impact of environmental effects on such indicators as productivity, income, and human health

- Using economic techniques to place values on environmental changes.

Key biophysical processes and related indicators of NRM status are explored in this volume with foci on the soil (Pathak et al., Chapter 3), water resources (Sahrawat et al., Chapter 4), and ecosystem services (Wani et al., Chapter 5). Shiferaw et al. (Chapter 2), discuss several methods for placing economic values on non-market ecosystems services, while Drechsel et al. (Chapter 9) provide examples of applying some of the commonly used valuation methods to valuing changes in soil fertility. 


\section{Challenges in NRM Impact Assessment}

Apart from the general challenges of attribution and selection bias in impact analysis, there are special conceptual and methodological challenges that arise from several unique features of natural resource management. NRM impact assessment needs to address important challenges of attribution, measurement, spatial and temporal scales, multidimensional outcomes, and valuation. The cross-commodity and integrated nature of NRM interventions makes it very challenging to attribute impact to any particular one among them. In crop genetic improvement where the research outputs are embodied in an improved seed, it is less difficult to attribute yield improvements to the investment in research. Changes in NRM frequently involve observable research products adopted by farmers as well as qualitative information about recommended management practices. Knowledge about such improved management practices may be transmitted through formal and informal outreach activities and by the self-experimentation and indigenous knowledge of the farmers themselves. In many cases, for such knowledge and information-based changes in NRM practices, it is difficult to identify the impacts attributable to the intervention. Also, it is not uncommon for different agencies to be involved in the development and promotion of new NRM technologies, making it hard to separate the impacts attributable to specific programmes. For example, in the evaluation of watershed programmes in India, it was difficult to attribute improvements in resource conditions and farm incomes to specific interventions, since increased participation and collaboration among a range of $\mathrm{R} \& \mathrm{D}$ partners was identified as a significant determinant of success (Kerr, 2001). The fact that most agricultural NRM interventions are information-based but not embodied in an easily measured package vastly complicates the attribution of observed impacts.

Identifying an appropriate counterfactual in NRM interventions is particularly challenging because quantifying the biophysical impacts of interventions on natural resources can be costly, imprecise, and slow. For NRM interventions that aim to halt resource degradation, the counterfactual may be a significant productivity decline. Hence, a properly measured counterfactual may reveal that achieving non-declining productivity represents a major gain over what would otherwise have occurred.

Identifying appropriate spatial boundaries for assessing NRM impact is often fraught with difficulty (Campbell et al., 2001; Sayer and Campbell, 2001). Agricultural NRM typically involves different spatial scales, from farmers' fields to entire watershed catchments, implying that many levels of interaction may need to be considered in assessing the impacts of research interventions. Multiple scales of interaction create upstream and downstream effects that complicate impact assessment. For example, assessing the impact of land use interventions in a watershed may need to take into account multiple interactions on different scales because erosion and runoffs in the upper watershed may not have the same impact on water quality downstream. It is also likely that interventions could have different effects, which in some cases can generate opposite impacts on different spatial scales. For example, 
soil and water conservation interventions can have a positive impact on crop yields upstream but negative impacts by reducing water availability downstream when water is a limiting factor for production, or positive impacts by reducing sedimentation, runoff and flooding when water is not a limiting factor.

In the temporal dimension, methodological challenges for NRM impact assessment arise from slow-changing variables and substantial lags in the distribution of costs and the benefits. For example, soil loss, exhaustion of soil fertility, and depletion of groundwater resources take place gradually and over a long period of time. In some cases it may be difficult to perceive the costs or the benefits of interventions to reverse these problems. In other cases, assessing the full range of the impacts of investments related to these slow-changing variables in a holistic manner may involve intensive monitoring of multiple biophysical indicators on different spatial scales over long periods of time. These factors make impact monitoring and assessment of NRM interventions a relatively slow and expensive process. Differences in time scale for the flow of costs and benefits are translated into lags in the distribution of costs and benefits that complicate impact assessment. Typically, costs are incurred up-front while delayed benefits accrue in incremental quantities over a long period of time (Pagiola, 1996; Shiferaw and Holden, 2001). For example, the benefits from the biodiversity that is used in genetic improvement of crop and animal varieties accrue in the long term but costs of in situ and ex situ conservation are incurred in the short term. The timing of an intervention can also affect its impact. This is, for example, the case for improved crop management practices that require optimising sowing date, fertiliser application, weeding and harvesting.

When outcomes are delayed and tend to vary according to local biophysical conditions, simulation models can facilitate the ex ante evaluation of NRM technology options that fit micro-climatic and agro-ecological niches. Biophysical process models are mainly used to explore the biophysical and productivity impacts of changes in agricultural and NRM practices (Wani et al., Chapter 5, this volume). Bioeconomic models, on the other hand, interlink economic and biophysical information to simulate optimal resource use and investment behaviour (Holden, Chapter 8, this volume; Shiferaw and Holden, Chapter 12, this volume). Both kinds of models require biophysical and experimental agronomic data to calibrate and validate them to local conditions.

NRM interventions may generate multidimensional biophysical outcomes across resource, environmental and ecosystem services. These might include changes in the quality and movement of soil, quantity and quality of water, sustainability of natural resources, and conservation of biodiversity. Appropriate indicators are needed to monitor the impacts of NRM interventions on the biophysical conditions of the soil (Pathak et al., Chapter 3, this volume), water resources (Sahrawat et al., Chapter 4, this volume), and the flow of ecosystem services that support agro-ecosystems (Wani et al., Chapter 5, this volume). The multidimensionality of outcomes from NRM interventions means that impact assessment often faces difficult 
measurement challenges, including very different measurement units and potentially the integration of very different natural resource outputs into some kind of uniform aggregate yardstick (Byerlee and Murgai, 2001).

The multidimensionality of NRM outcomes extends to those directly or indirectly affecting human beings. NRM interventions can generate environmental and health benefits whose values might not be reflected in current markets, but on which society places a value for multiple reasons. For example, water and water-based ecosystems provide not only direct values in consumptive uses (e.g. fishing, irrigation) and non-consumptive uses (e.g. aesthetic value), but also indirect use values such as ecosystem functions and services, option values for possible future uses and applications and nonuse values for intrinsic significance (existence and heritage value). Empirical valuation of non-market benefits is explored by Shiferaw et al. (Chapter 2, this volume). But depending on how NRM ideas are conveyed, the human outcomes may extend even further. Integrated NRM projects engage in participatory activities that may empower individuals and communities in ways that extend far beyond the realm of agricultural NRM, as discussed by Douthwaite et al. (Chapter 14, this volume).

\section{Approaches for Assessing NRM Impacts}

Impact assessment for NRM interventions ultimately needs to show the social costs and benefits associated with the research, promotion, and adaptation of these interventions. Given the complexities and challenges associated with measuring, monitoring and valuing such changes, moreinnovativeassessment methods are required. An important factor that needs to be considered in the selection of appropriate methods is the capacity to account for nonmonetary impacts that NRM interventions generate in terms of changes in the flow of resource and environmental services that affect sustainability and ecosystem health. As discussed earlier, a mix of quantitative and qualitative methods may be the optimal approach for capturing on-site and off-site monetary and non-monetary impacts. The economic surplus approach is the commonly used method for evaluating the impacts of agricultural research investments, particularly for crop improvement technologies. This approach estimates benefits as changes in 'economic surplus' (the aggregate value that consumers are willing to pay above and beyond what it costs producers to supply the good or service in question). The cumulative benefits are then compared to cumulative R\&D costs over time. Specifics and the challenges of incorporating non-marketed on-site effects and off-site externalities are discussed by Swinton (Chapter 7, this volume), with Bantilan et al. (Chapter 11, this volume) providing an empirical application.

Promising analytical methods that can be used to quantify economic changes due to NRM interventions include econometrics (Alston et al., 1995) and bioeconomic optimisation modelling. For example, econometric methods can be used in empirically estimating the demand for marketed or certain non-marketed goods and services, providing elasticities for 
calculations of economic surplus. Econometric methods can also be used to link a time-series of measures of output, costs and profits directly to past R\&D investments (Alston et al., 1995). Likewise, they can be used to establish statistical relationships between changes in NRM practices and measured performance indicators, such as land productivity, total factor productivity, production costs, net farm income, or income volatility. Pender (Chapter 6, this volume) discusses the conceptual and empirical issues while Kerr and Chung (Chapter 10, this volume) provide an empirical application of this method.

Bioeconomic modelling nests essential biophysical processes within economic behavioural models. Their constrained optimisation perspective allows evaluating how technological and/or policy changes would affect economic welfare, sustainability, and environmental conditions over time. The integrated framework captures biophysical process evolution along with rational human management responses. Holden offers a conceptual treatment of bioeconomic modelling (Chapter 8, this volume), while Shiferaw and Holden provide an empirical application for a farm household (Chapter 12, this volume) and Holden and Lofgren demonstrate the use of an economywide computable general equilibrium model for evaluating NRM technology and policy impacts (Chapter 13, this volume).

As a response to the complexities that impact assessment practitioners face in evaluating the multi-faceted impacts of NRM, there is an increasing interest in developing more holistic and 'softer' assessment methods. Integrated natural resource management (INRM) calls for participatory NRM interventions at multiple scales with frequent adaptive feedback and multiple stakeholders (who often hold contrasting objectives) (Campbell et al., 2001; Sayer and Campbell, 2001). Douthwaite et al. (Chapter 14, this volume) explore the conceptual underpinning of the INRM framework and its implications for evaluating NRM impacts.

\section{Organisation of the Book}

The chapters in this book address the conceptual framework, methodological challenges and selected empirical experiences of NRM impact assessment. In so doing, they explore many of the complexities identified in this introductory overview. The book's 16 chapters are organised into five parts. Following this initial part that introduces the challenges and approaches to NRM impact assessment, Part II includes four chapters that deal with the valuation of ecosystem services and the measurement of biophysical indicators of NRM impacts. Part III introduces advances in methods used to evaluate the economic and environmental impacts of NRM technology and policy interventions. Part IV deals with NRM impact assessment in practice. Five case studies illustrate the methodological advances discussed in Part III. The final part of the book (Part V) highlights some of the existing controversies and outlines best practices, research issues, and recommendations for NRM impact assessment into the future. 


\section{Endnote}

${ }^{1}$ One way to enhance ethical and political acceptability of randomisation is to phase the intervention such that some groups gain access to programme benefits at a later stage. In this way the random selection determines when a given group gains access to the benefit, not if they receive it.

\section{References}

Alston, M.J., Norton, W.G. and Pardey, P.G. (1995) Science Under Scarcity. Principles and Practice for Agricultural Research Evaluation and Priority Setting. Cornell University Press, Ithaca, New York, USA, and London, UK, 585 pp.

Alston, M.J., Chan-Kang, C., Marra, M.C., Pardey, P.G. and Wyatt, T.J. (2000) A metaanalysis of rates of return to agricultural R\&D: exe pede herculem? Research Report 113. International Food Policy Research Institute (IFPRI), Washington, DC, 159 pp.

Baker, J.L. (2000) Evaluating the Impacts of Development Projects on Poverty. A Handbook for Practitioners. World Bank, Washington, DC, 230 pp.

Bamberger, M. (2000) Integrating Quantitative and Qualitative Methods in Development Research. World Bank, Washington, DC, 189 pp.

Barrett, C.B. (2003) Natural Resources Management Research in the CGIAR: A MetaEvaluation in The CGIAR at 31: An Independent Meta-Evaluation of the Consultative Group on International Agricultural Research. World Bank, Washington, DC, 217 pp.

Byerlee, D. and Murgai, R. (2001) Sense and sustainability revisited: the limits of total factor productivity measures of sustainable agricultural systems. Agricultural Economics 26(3), 227-236.

Campbell, B., Sayer, J.A., Frost, P., Vermeulen, S., Ruiz-Perez, M., Cunningham, A. and Ravi, P. (2001) Assessing the performance of natural resource systems. Conservation Ecology 5(2), 32. [online] http:/ / www.ecologyandsociety.org/vol5/ iss $2 /$ art22/index.html

Delgado, C.L., Wada, N., Rosegrant, M.W., Meijer, S. and Ahmed, M. (2003) Outlook for Fish to 2020. Meeting the Global Demand. International Food Policy Research Institute, Washington, DC, $28 \mathrm{pp}$.

Friedlander, D. and Robins, P.K. (1995) Evaluating program evaluations: New evidence on commonly used non-experimental methods. American Economic Review 85, 923-937.

Greene, W.H. (1997) Econometric Analysis, $3^{\text {rd }}$ edn. Prentice Hall, Upper Saddle River, NJ, 1075 pp.

Heckman, J. and Robb, R. (1985) Alternative methods of evaluating the impact of interventions: An overview. Journal of Econometrics 30, 239-267.

Heckman, J. and Smith, J.A. (1995) Assessing the case for social experiments. Journal of Economic Perspectives 9(2), 85-110.

Izac, A.N. (1998) Assessing the Impact of Research in Natural Resources Management. The World Agroforestry Centre (ICRAF), Nairobi, Kenya, 38 pp.

Kerr, J. (2001) Watershed project performance in India: conservation, productivity and equity. American Journal of Agricultural Economics 83, 1223-1230.

Mohr, L.B. (1995) Impact Analysis for Program Evaluation, $2^{\text {nd }}$ edn. Sage Publications, Thousand Oaks, California, $336 \mathrm{pp}$. 
Nelson, M. and Maredia, M. (1999) Environmental Impacts of the CGIAR: An Initial Assessment. Paper presented at the International Centers Week, October 2529, 1999, Washington, DC. Standing Panel for Impact Assessment, Food and Agriculture Organization of the United Nations, Rome, Italy, 71 pp. [online] http://www.sciencecouncil.cgiar.org/publications/pdf/envimp.pdf

Pagiola, S. (1996) Price policy and returns to soil conservation in semi-arid Kenya. Environmental and Resource Economics 8, 251-271.

Pingali, P. and Rosegrant, M. (1998) Supplying wheat for Asia's increasingly westernized diets. American Journal of Agricultural Economics 80(5), 954-959.

Rosegrant, M., Paisner, M.S., Meijer, S. and Witcover, J. (2001) Global Food Projections to 2020: Emerging Trends and Alternative Futures. IFPRI 2020 Vision. International Food Policy Research Institute (IFPRI), Washington, DC, 206 pp.

Sayer, J.A. and Campbell, B. (2001) Research to integrate productivity enhancement, environmental protection and human development. Conservation Ecology 5(2), 32. [online] http:/ / www.ecologyandsociety.org/vol5/iss2/art32/index.html.

Shiferaw, B. and Holden, S.T. (2001) Farm-level benefits to investments for mitigating land degradation: empirical evidence from Ethiopia. Environment and Development Economics 6, 335-358.

Shiferaw, B. and Freeman, H.A. (eds) (2003) Methods for Assessing the Impacts of Natural Resource Management Research. A Summary of the Proceedings of an International Workshop, 6-7 December 2002, International Crops Research Institute for the Semi-Arid Tropics (ICRISAT), Patancheru, India, $136 \mathrm{pp}$.

Valadez, J. and Bamberger, M. (eds) (1994) Monitoring and Evaluating Social Programmes in Developing Countries. The World Bank, Washington, DC, 536 pp.

World Bank (2001) Making Sustainable Commitments: An Environment Strategy for the World Bank. World Bank, Washington, DC, 280 pp.

World Bank (2002) Understanding Impact Evaluation. World Bank, Washington, DC. [online] http://www.worldbank.org/poverty/impact/index.htm

World Bank (2003) Environment Matters: Annual Review, July 2002 - June 2003. World Bank, Washington DC. [online] http://lnweb18.worldbank.org/ESSD/envext. nsf 